\title{
PROCESSAMENTO E INTERPRETAÇÃO DE DADOS GAMAESPECTROMÉTRICOS AÉREOS DO PROJETO ITABIRA-FERROS, MG: UMA FERRAMENTA NO AUXÍLIO AO MAPEAMENTO GEOLÓGICO
}

\author{
LEILA MÁRCIA MENDES CARVALHO ${ }^{1}$, AUGUSTO CÉSAR BITTENCOURT PIRES', \\ CLAUDINEI GOUVEIA DE OLIVEIRA ${ }^{2}$, ROBERTO ALEXANDRE VITÓRIA DE MORAES ${ }^{3}$ \\ \& MARCELO DE LAWRENCE BASSAY BLUM ${ }^{4}$
}

\begin{abstract}
Resumo A área de Itabira-Ferros está situada na região do Quadrilátero Ferrifero, Estado de Minas Gerais e é conhecida pelas abundantes ocorrências de esmeraldas. O presente trabalho discute as características geofísicas utilizando dados de gamaespectrometria aérea e a integração dos mesmos com dados geológicos para determinar prováveis zonas de mineralização de esmeraldas. A imagem do canal de contagem total permitiu definir um arcabouço gamaespectrométrico para a área. A análise do comportamento dos elementos $\mathrm{K}$, Th, $\mathrm{U}$ foi realizada em conjunto com as imagens ternárias RGB e CMY, sendo possível a separação de unidades e estruturas. No total foram delimitadas 16 unidades gamaespectrométricas distintas para essa região. Muitas dessas unidades são correlacionáveis à geologia conhecida, porém outras unidades não têm representação geológica em mapas. O mapa das interpretações estruturais gamaespectrométricas mostra que as mineralizações da região ocorrem em áreas profusamente falhadas, principalmente ligadas as bordas do sigmóide central da unidade III de deslocamento dúctil da área. As mineralizações conhecidas formam uma faixa, espécie de trend de direção NW-SE, ente duas falhas de mesma direção entre as cidades de João Monlevade e Dores de Guanhães. As mineralizações de esmeraldas permanecem na porção leste do sigmóide, enquanto que outras mineralizações de berilo (água-marinha e outros berilos) estão ligadas diretamente ao sigmóide, na parte central do sigmóide ou a outras feições NW que recortam a área.
\end{abstract}

Palavras-Chave: Gamaespectrometria aérea, mapeamento geológico, prospecção mineral, esmeraldas.

\begin{abstract}
PROCESSING AND INTERPRETATION OF AIRBORNE GAMMA-RAY SPECTROMETRIC DATA FROM ITABIRA-FERROS PROJECT, MG: A TOOL SUPPORTING GEOLOGICAL MAPPING AND MINERAL EXPLORATION. The area covered by the Itabira-Ferros Project is located in the Iron Quadrangle, State of Minas Gerais, and is known for its emerald occurrences. The present study applies geophysical characteristics, using airborne gamma-ray spectrometric data and their integration with geology, to determine probable zones of emerald mineralization. The total count gamma-ray image allows the definition of the spectrometric framework of the area. Analyses of the elements $\mathrm{K}$, Th, and U distribution were conducted together with RGB and CMY ternary images, leading to the identification of spectrometric geological units and structures. A total of 20 gamma-ray spectrometric units is identified for the region. Most of them are correlated to mapped units geological and others with no apparent correlation. A map with interpreted gamma-ray spectrometric structures shows that mineralizations are located in areas of extreme faulting, specially at the edges of the sigmoidal feature in unit III, reflecting ductile displacement. Known mineralizations form a belt, trend like structure in NW-SE direction, between two faults in the same direction and the cities of João Monlevade and Dores de Guanhães. Emerald mineralizations are located in the eastern portion of the sigmoid, others mineralizations are directly related to the sigmoid at its central portion and to other NW features cutting the area.
\end{abstract}

Keywords: airborne gamma-ray, geological and structural mapping, mineral exploration, emerald.

INTRODUÇÃo A gamaespectrometria normalmente se propõe estudar as variações das concentrações de potássio, urânio e tório e suas distribuições espaciais. A espectrometria raios gama quando feita através de recobrimento aéreo possibilita a delimitação de diferentes litotipos e o delineamento de traços estruturais, permitindo o fornecimento de subsídios para a cartografia geológica, sendo largamente utilizados em trabalhos relacionados com mapeamento geológico e prospecção mineral (Vasconcellos et al. 1990).

A área pesquisada está limitada pelos paralelos $19^{\circ} 50^{\prime} 06^{\prime \prime S}$ -

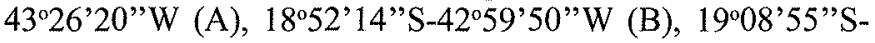
$42^{\circ} 45^{\prime} 29^{\prime \prime} \mathrm{W}$ (C) e $20^{\circ} 06^{\prime} 47^{\prime \prime} \mathrm{S}-43^{\circ} 12^{\prime} 06^{\prime \prime} \mathrm{W}$ (D) (Figura 1), correspondendo a uma superfície de $4.600 \mathrm{~km}^{2}$ na porção centro-sudeste do Estado de Minas Gerais.

CONTEXTO GEOLÓGICO A região do Projeto ItabiraFerros está contida na Província Estrutural Mantiqueira (Almeida et al. 1976) e insere-se no contexto da Faixa de Dobramentos
Araçuaí, MG. Ela tem sido alvo de muitos estudos nessa última década, com significativo avanço através de modelos evolutivos mais consistentes.

Ela é constituída por rochas arqueanas e proterozóicas, incluindo terrenos polimetamórficos de baixo a alto grau. São representados por gnaisses TTG, com rochas máficas e ultramáficas associadas, seqüências vulcanossedimentares tipo greenstone belts (Supergrupo Rio das Velhas) e seqüências ferriferas paleoproterozóicas do Supergrupo Minas do extremo nordeste do Quadrilátero Ferrífero (Schorscher 1991, Oliveira \& Leite 2000; Figura 2).

Na região de Itabira-Ferros são descritos corpos graníticos (Granitos Borrachudos), encaixados nesses corpos ocorrem rochas xistosas, interpretadas como pertencentes ao greenstone belt Rio das Velhas.

As mineralizações de esmeraldas da área estão inseridas em terrenos vulcanossedimentares de idade arqueana a proterozoica, representadas pelo greenstone belt Rio das Velhas (Oliveira

\footnotetext{
1 - Laboratório de Geofísica Aplicada, Universidade de Brasília, e-mail: lmmc!@unb.com.br

2- Universidade de Brasília.

3 - HGeo-Tecnologia em Geociências.

4 - Instituto Nacional de Criminalistica (INC/DITEC/DPF).
} 


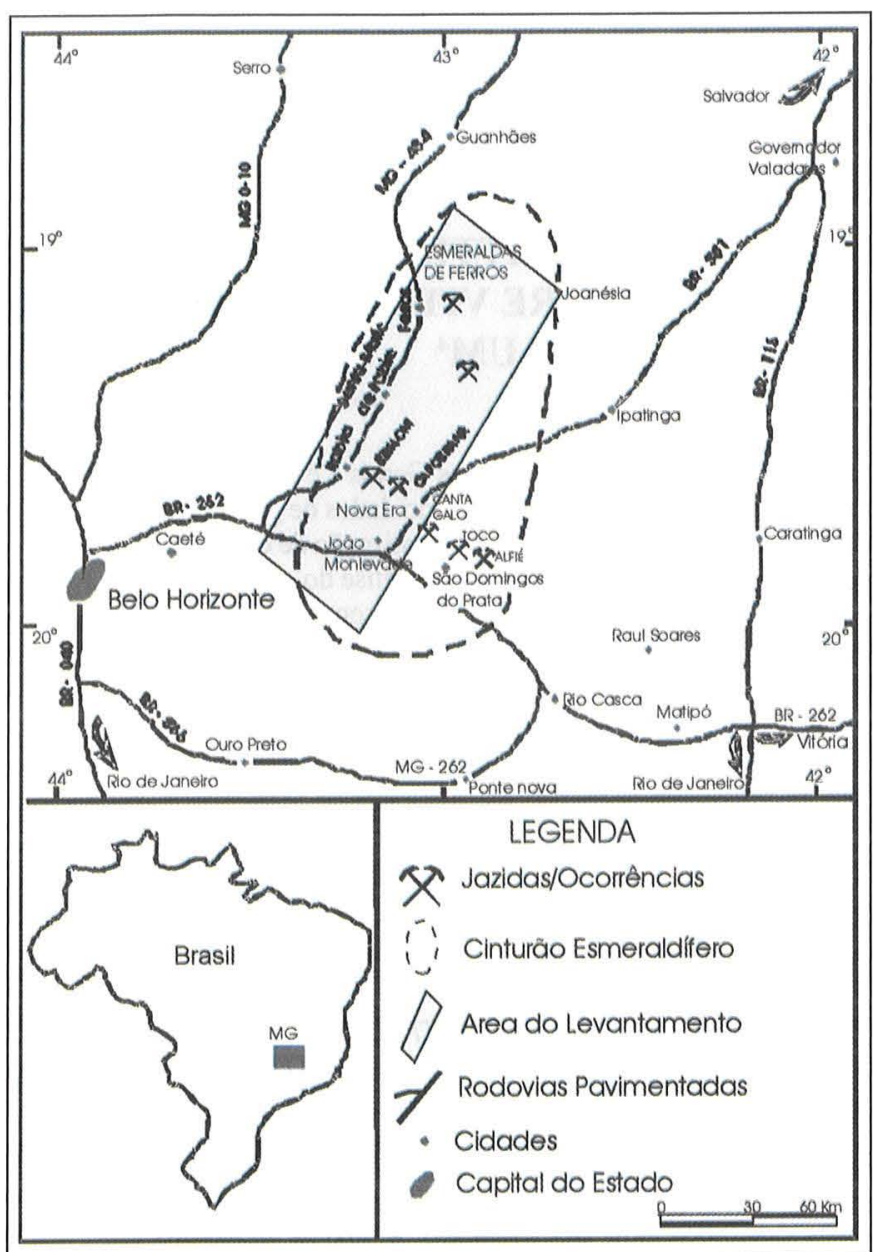

Figura 1: Mapa de localização do Cinturão Esmeraldifero delimitado para a região de Itabira-Ferros, $M G$ (modificado de Souza et al. 1992)

\& Leite 2000), em que a formação das esmeraldas deve-se a interação de fluidos pegmatíticos, provenientes dos Granitos Borrachudos com as rochas básicas/ultrabásicas. Essas rochas originaram, durante os processos metamórficos, os tipos xistosos denominados de biotitas/flogopitas xistos ou biotititos/flogopititos que hospedam esses minerais (Schorscher 1991).

Além desses são descritos importantes corpos pegmatíticos e veios de quartzo, concordantes ou não com as estruturas gerais da área. Esses litotipos estão deformados e metamorfizados na fácies xisto verde alto a anfibolito. O controle estrutural é marcado, principalmente por falhas de empurrão, zonas de cisalhamento transcorrentes e dobras recumbentes.

TÉCNICAS Usando o sistema Oásis Montaj ${ }^{\mathrm{TM}}$ 5.1, os dados de gamaespectrometria foram tratados buscando-se obter uma melhor qualidade de apresentação, e posteriormente processados gerando mapas adequados para interpretação. Para tal, foi necessária a aplicação de uma série de procedimentos que tiveram inicio com a filtragem dos dados.

O processamento dos dados foi feito a partir da verificação de valores ausentes ou espúrios (picos), da distribuição e a densidade espacial dos dados. O conjunto de dados mostrou-se uniforme com a mesma densidade de pontos em todas as linhas de vôo e o padrão geral não apresentou grandes problemas.

A transformação do conjunto de dados para uma malha regular foi feita com o apoio do método de curvatura mínima. Em função do espaçamento entre as linhas de vôo (500 metros), op-

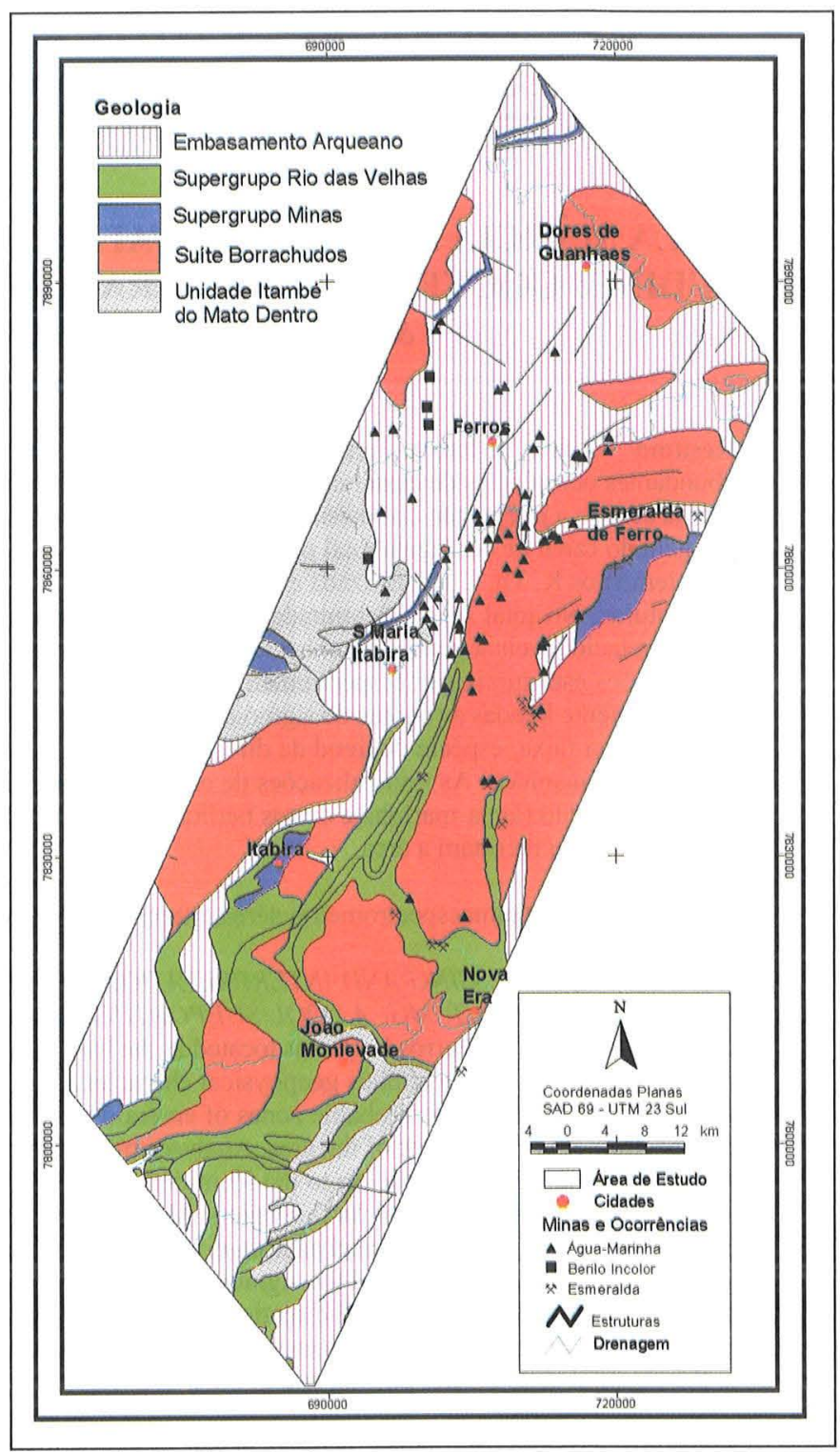

Figura 2: Mapa geológico da área em estudo (CPRM 2004).

tou-se por uma célula quadrada de 200 metros de lado. A técnica de micronivelamento utilizada foi àquela proposta por Minty (1991) com o apoio do algoritmo microlevel desenvolvido por Blum (1999).

PROCESSAMENTO DOS DADOS Compreendeu a geração dos temas usuais para a interpretação gamaespectrométrica, imagens de $\mathrm{K}$, Th, U, Contagem Total (CT), das razões Th/K, U/K e U/Th e imagens compostas RGB (K/Th/U) e CMY $(\mathrm{K} / \mathrm{Th} / \mathrm{U})$ (Figuras 3, 4, 5, 6, 7, 8, 9, 10 e 11, respectivamente). Todas as imagens foram posteriormente sobrepostas ao modelo digital de terreno de forma a facilitar e objetivar a interpretação qualitativa em termos de unidades geofísicas e de suas estruturas.

Todas as interpretações e integrações foram feitas em ambiente de Sistema de Informações Geográficas (SIG), o que facilita as fases de análise e de apresentação dos resultados finais.

A imagem do canal de potássio (Figura 3) mostra áreas com concentração anômala do potássio, observadas principalmente nas porções centro-oeste e sudoeste da área e que grande parte desse elemento pode ter sido lixiviado. A imagem do tório (Figura 4) mostra que as maiores concentrações desse elemento tem uma estreita relação com as áreas de topografia mais ele- 


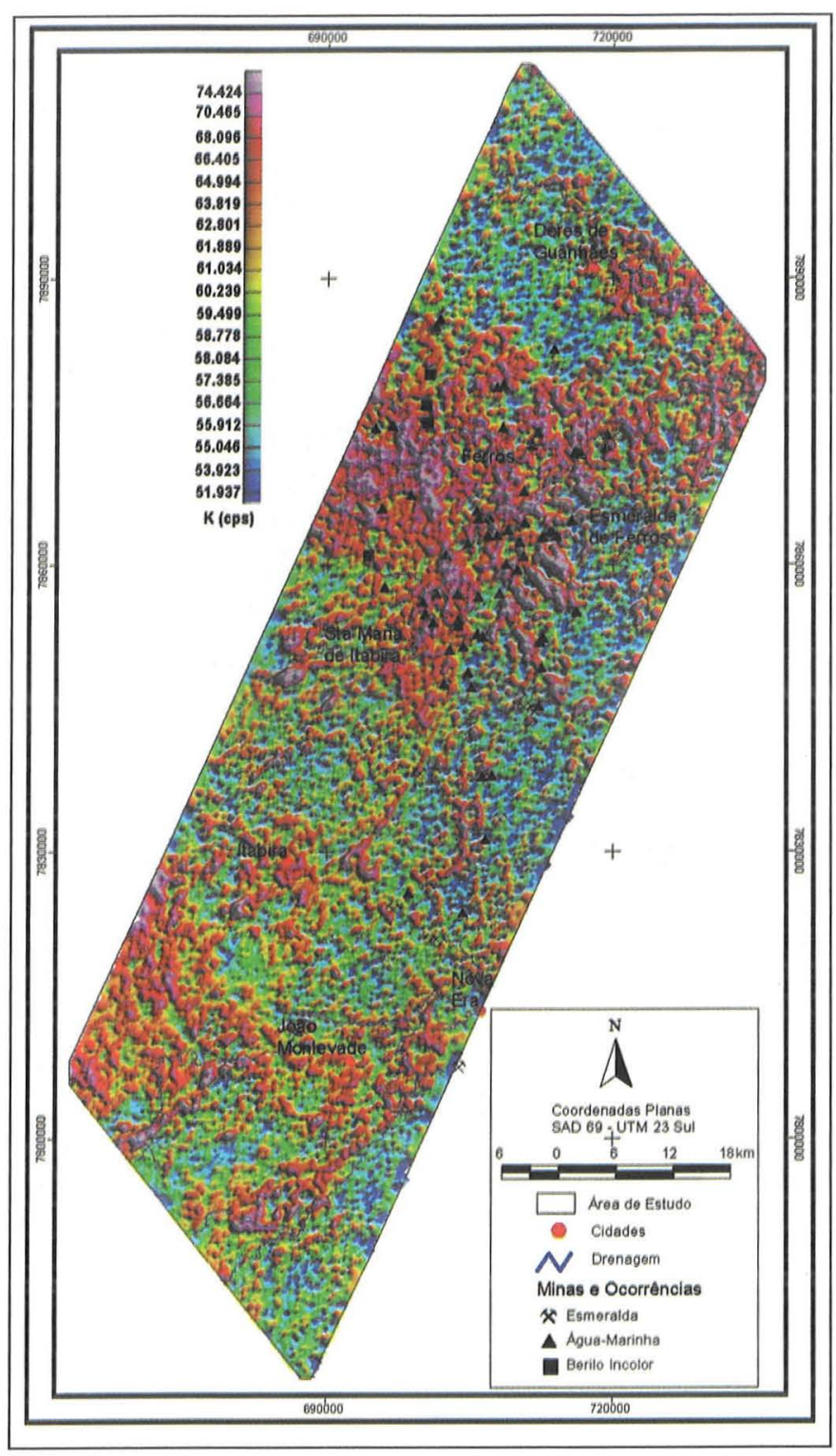

Figura 3: Imagem do canal de Potássio.

vada. Na parte central da área tem uma estrutura em forma de sigmóide que mostra baixas concentrações desse elemento. $\mathrm{Na}$ porção centro-leste da área há uma estrutura levemente arqueada com alta concentração de tório nas partes mais altas de sua topografia. Já na porção sul, há alguns platôs com concentrações elevadas de tório, porém, predomina uma baixa concentração desse elemento nessa região.

Concentrações mais elevadas desse radioelemento são observadas nos platôs da área (porções sul, centro-oeste, centroleste e NNW da área; Figura 5). A estrutura em forma de sigmóide da parte central da área mostra concentrações elevadas desse elemento. O mesmo é observado na estrutura levemente arqueada da área centro-leste.

A imagem do canal de contagem total (Figura 6) possibilitou fazer uma análise conjunta das discriminações para que se tenha uma idéia do que efetivamente contribuiu na formação do relevo gamaespectrométrico retratado neste canal. Nela também foi possível estudar os lineamentos que, em maioria, representaram contatos entre as grandes unidades gamaespectrométricas.

A imagem da razão Th/K da área pesquisada (Figura 7) possibilitou interpretar a distribuição do potássio relacionado a possíveis zonas de alteração hidrotermal.

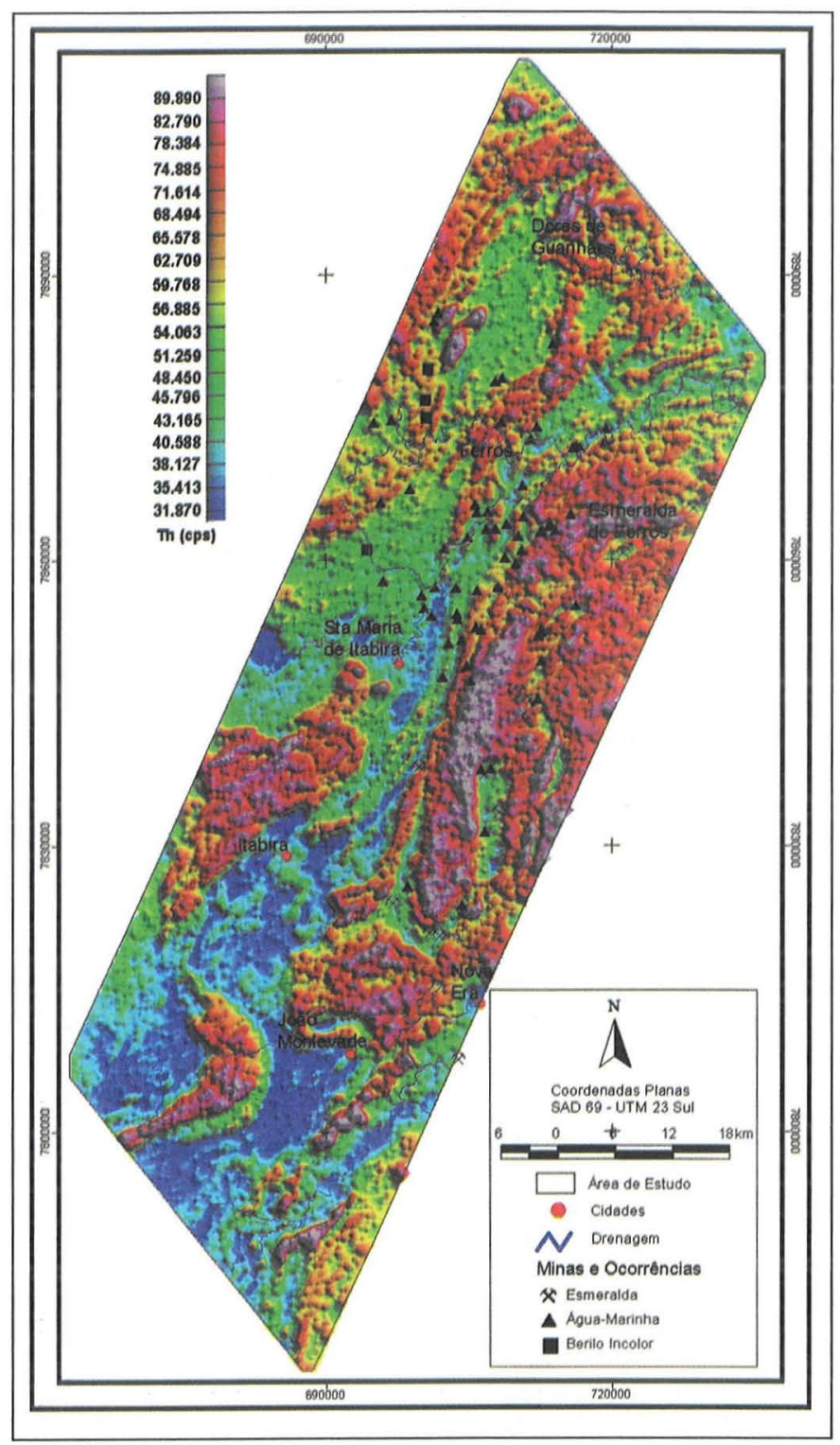

Figura 4: Imagem do canal de Tório.

A área caracterizou-se por valores variados de concentrações dessa razão. As áreas com valores mais baixos dessa razão encontra-se em sua maioria associada a regiões de topografia mais baixa, como os vales e as drenagens. As áreas de concentração alta dessa razão encontram-se associadas aos platôs.

A imagem U/K (Figura 8) propiciou uma boa discriminação de litotipos, marcando inclusive variações composicionais internas de algumas unidades. As áreas de topografia mais baixa, vales e drenagens, caracterizam-se por uma concentração baixa a média-baixa dessa razão. As áreas topograficamente mais altas, platôs, mostram enriquecimentos elevados de U/K.

A imagem da razão U/Th (Figura 9) mostra uma grande faixa, com direção NE-SW com enriquecimento elevado dessa razão, além da porção sul da área. Concentrações moderadas são observadas na porção centro-oeste e no extremo norte. Uma grande feição em forma de U é observada no centro-leste da área e mostra uma concentração moderada de U/Th. No restante da área a concentração de U/Th varia de média-baixa a baixa.

A análise do comportamento dos elementos, bem como da distribuição de cada um desses elementos com a topografia foi realizada em conjunto com as imagens ternárias RGB (Figura 10) e CMY (Figura 11), sendo possível a separação das unidades 


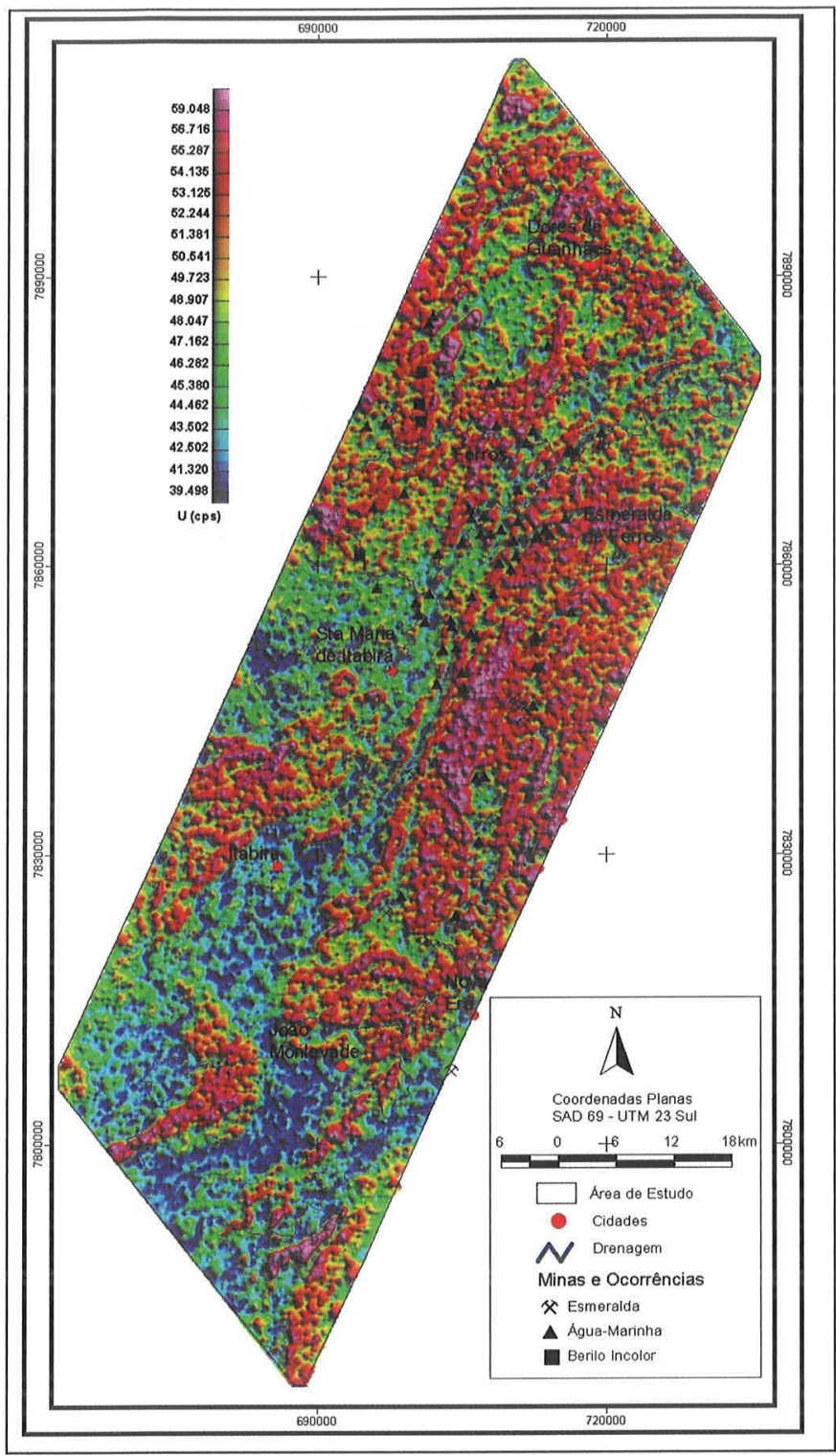

Figura 5: Imagem do canal de Urânio.

e estruturas, resultando em um mapa litoestrutural gamaespectrométrico.

No total foram delimitadas 20 unidades gamaespectrométricas distintas para essa região. Com base nas respostas radiométricas, de acordo com as misturas de cores, vermelho, verde e azul, permitiu agrupá-las ainda em cinco categorias de acordo com o teor dos radioelementos (Figura 13):

\footnotetext{
1) baixas concentrações: 0-19\%;

2) baixa-média: $20-39 \%$;

3) média: 40-59\%;

4) média-alta: $60-79 \%$;

5) alta: $80-100 \%$.
}

As características de cada unidade, em função de seu conteúdo de K, Th e U estão mostrados na figura 13 .

LINEAMENTOS GAMAESPECTROMÉTRICOS A análise de todas as imagens gamaespectrométricas permitiu retirar lineamentos que definem interrupções e descontinuidades das respostas radiométricas, em que a maioria representa contatos entre as grandes unidades, onde alguns parecem representar

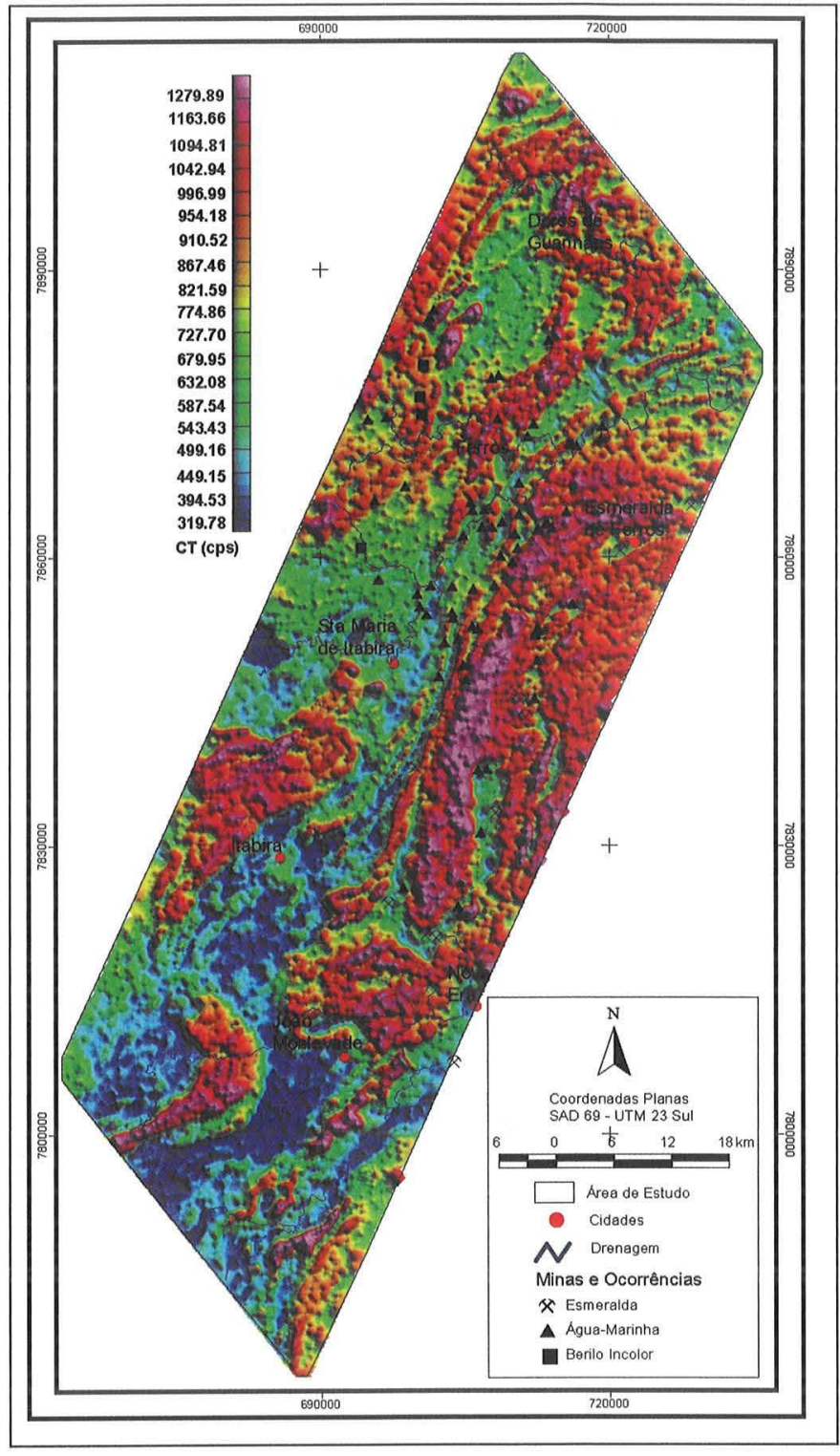

Figura 6: Imagem do canal de Contagem Total.

zonas de cisalhamento (Figura 12).

Os lineamentos ocorrem segundo uma direção principal NE$\mathrm{SW}$, variando de $\mathrm{N} 30^{\circ}-50^{\circ} \mathrm{E}$ e apresentam grandes extensões, em alguns casos cortando toda a área.

Um segundo conjunto de estruturas tem orientações $\mathrm{N} 30^{\circ}$ $50^{\circ} \mathrm{W}$. Um terceiro conjunto de estruturas encontra-se na direção E-W, com valores variando entre $80^{\circ}-100^{\circ} \mathrm{Az}$. Já um quarto conjunto, porém com menor quantidade em área, se encontra na direção $0^{\circ}$ a $10^{\circ} \mathrm{Az}$

Essas estruturas são importantes porque representam zonas de fraqueza por onde circulam fluidos mineralizantes.

INTEGRACÃO DOS DADOS A superposição dos mapas dos domínios gamaespectrométricos e das estruturas gamaespectrométricas gerou o mapa integrado (Figura 13). Mostra, assim, o somatório das informações discutidas acima as quais possibilitam a geração de um quadro gamaespectrométrico. Este ressalta as características de emissividade gama peculiar às unidades litológicas e pedológicas aflorantes na área do levantamento. É, portanto, o quadro mais facilmente reconhecível nos trabalhos de fotointerpretação e, certamente, nos de geologia de campo. 


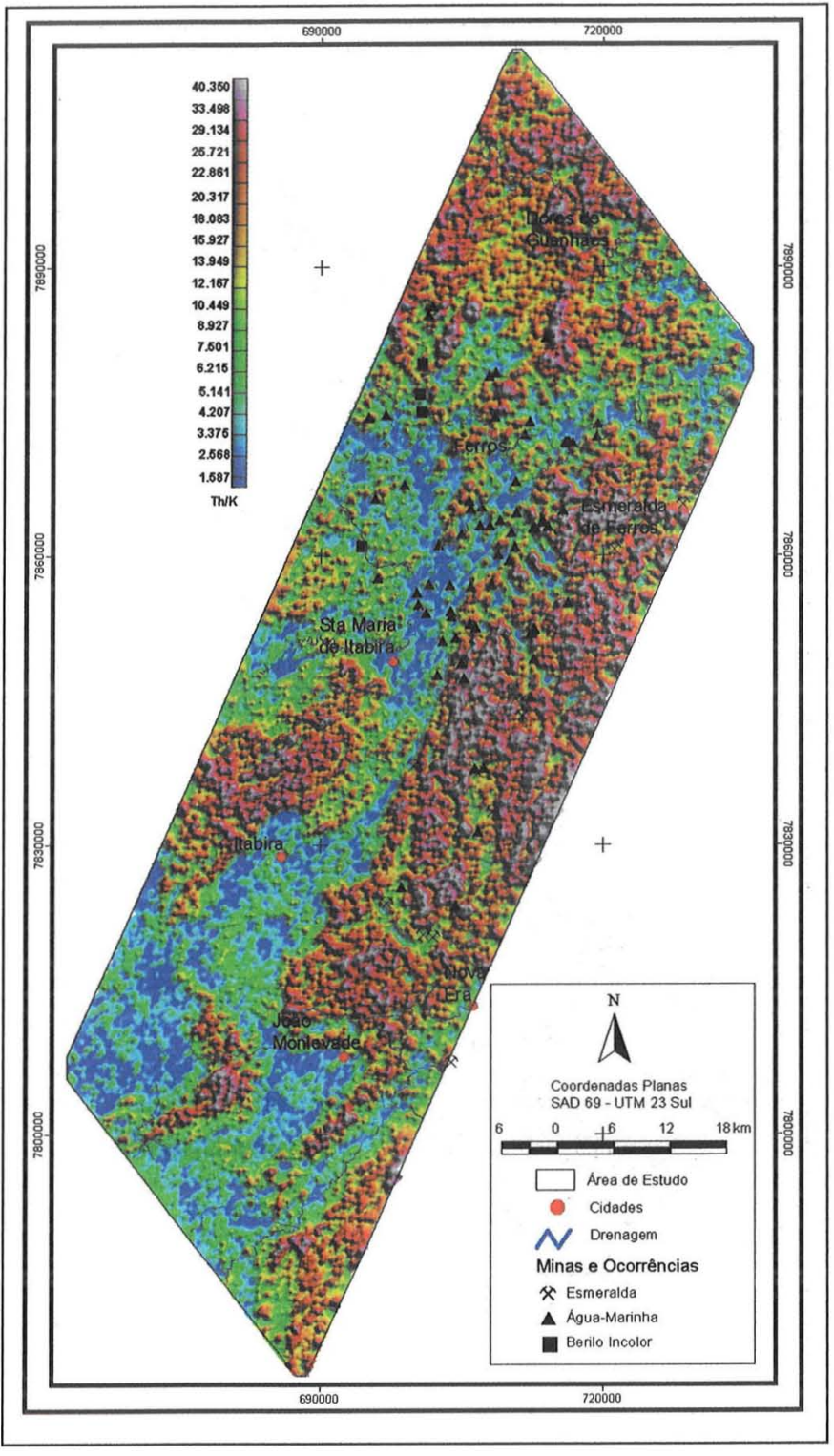

Figura 7: Imagem da razãoTh/K.

INTEGRAÇÃO GEOFÍSICA-GEOLOGIA E DISCUSSÕES Embora as unidades gamaespectroméricas sejam distintas entre si, há uma tentativa de correlação com a geologia conhecida.

Assim, com relação ao mapeamento geológico (Figura 2), a gamaespectrometria revelou um conjunto de assinaturas cuja checagem em campo pode acrescentar detalhes, e muitos, sobre a distribuição dos litotipos formadores do que seria esta geologia na região.

Uma análise detalhada desses subdomínios (Figura 13) mostrou que as unidades $3 \mathrm{gm}$ representam os granitos da Suíte Borrachudos. Essa unidade é caracterizada por conteúdos relativamente médios de potássio e enriquecimento em tório e urânio. O potássio tende a se concentrar nas bordas e encostas, enquanto o tório tende a se concentrar nos topos. A resposta mostrou também que houve um grande lixiviamento de potássio para as unidades do embasamento. Já quando se faz uma comparação da composição entre os diversos corpos borrachudos observa-se que não há grandes variações entre eles.

O corpo da porção centro-leste (Corpo Açucena) é recortado pela unidade SGRv2 que representa unidade máficas, provavelmente unidades do Supergrupo Rio das Velhas. A porção

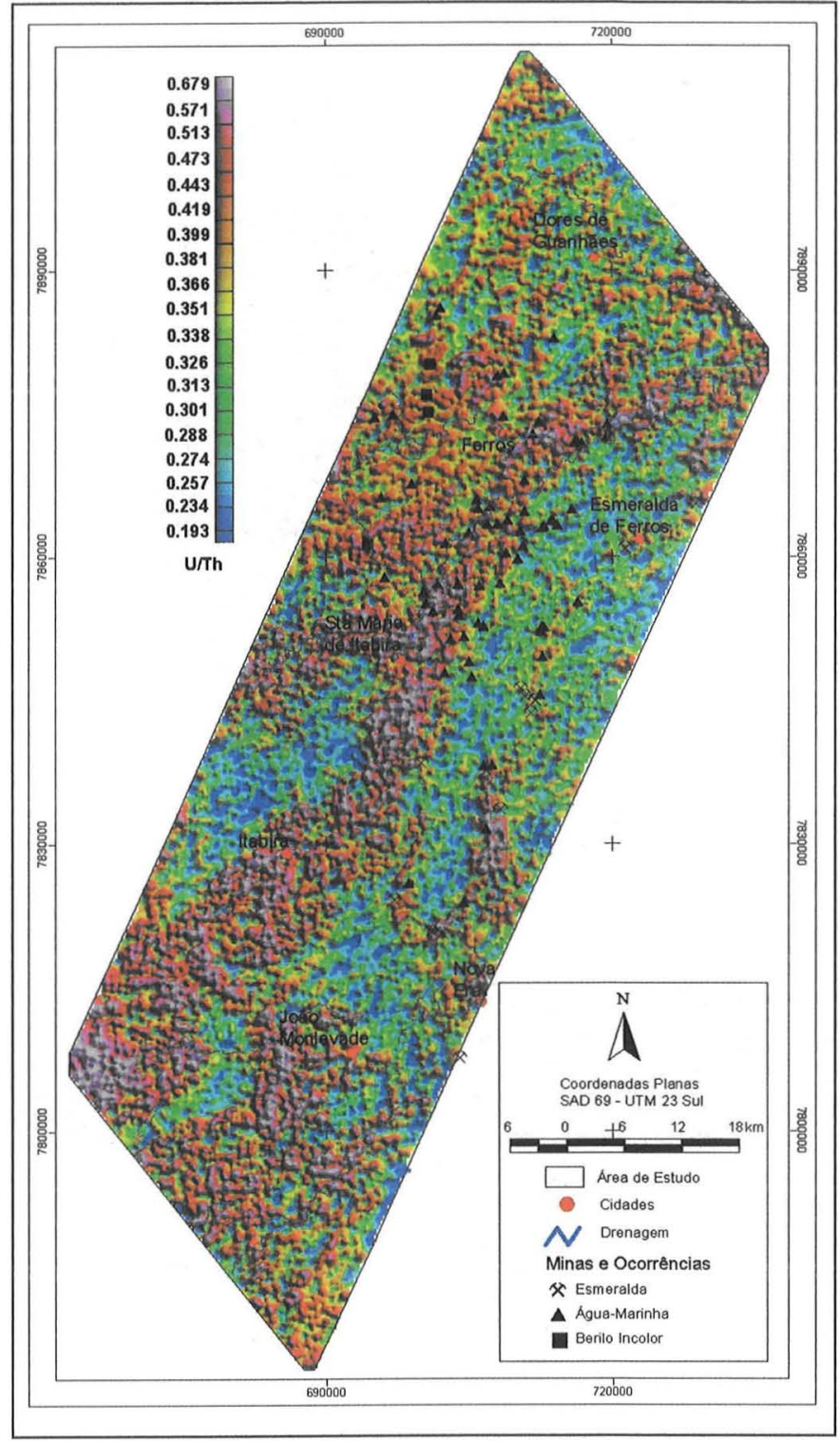

Figura 8: Imagem da razão U/K.

N-NW da área, em mapa, é representada pelo granito Senhora do Porto (Suíte Borrachudos, Folha Conceição do Mato Dentro), porém as respostas gamaespectrométricas mostram rochas com contagens muito variadas, não sendo possível correlacionar somente a um corpo. Foram observados também rochas ricas nos elementos urânio e tório e que não têm uma representação geológica em mapa.

Pequenos corpos podem ser delimitados dentro dos subdomínios $3 \mathrm{gm}$ e Cg, com conteúdos relativamente semelhantes aos observados para os granitos da Suíte Borrachudos, porém com teores mais elevados dos três elementos, poderiam representar fases tardias desses corpos.

De acordo com o mapa geológico (Figura 2), a porção N/ NW da área tem como embasamento o Complexo Guanhães. Porém as imagens gamaespectrométricas mostram grandes variações composicionais nessa região, com enriquecimentos significativos em urânio e tório, sendo possível delimitar diversos subdomínios, não tendo, os mesmos, correspondência à geologia conhecida.

Já em relação às rochas do embasamento (unidade 6 centro, sul, sudoeste e sudeste; 13 , centro-norte e 20 noroeste da área), de acordo com as imagens ternárias, percebeu-se que es- 


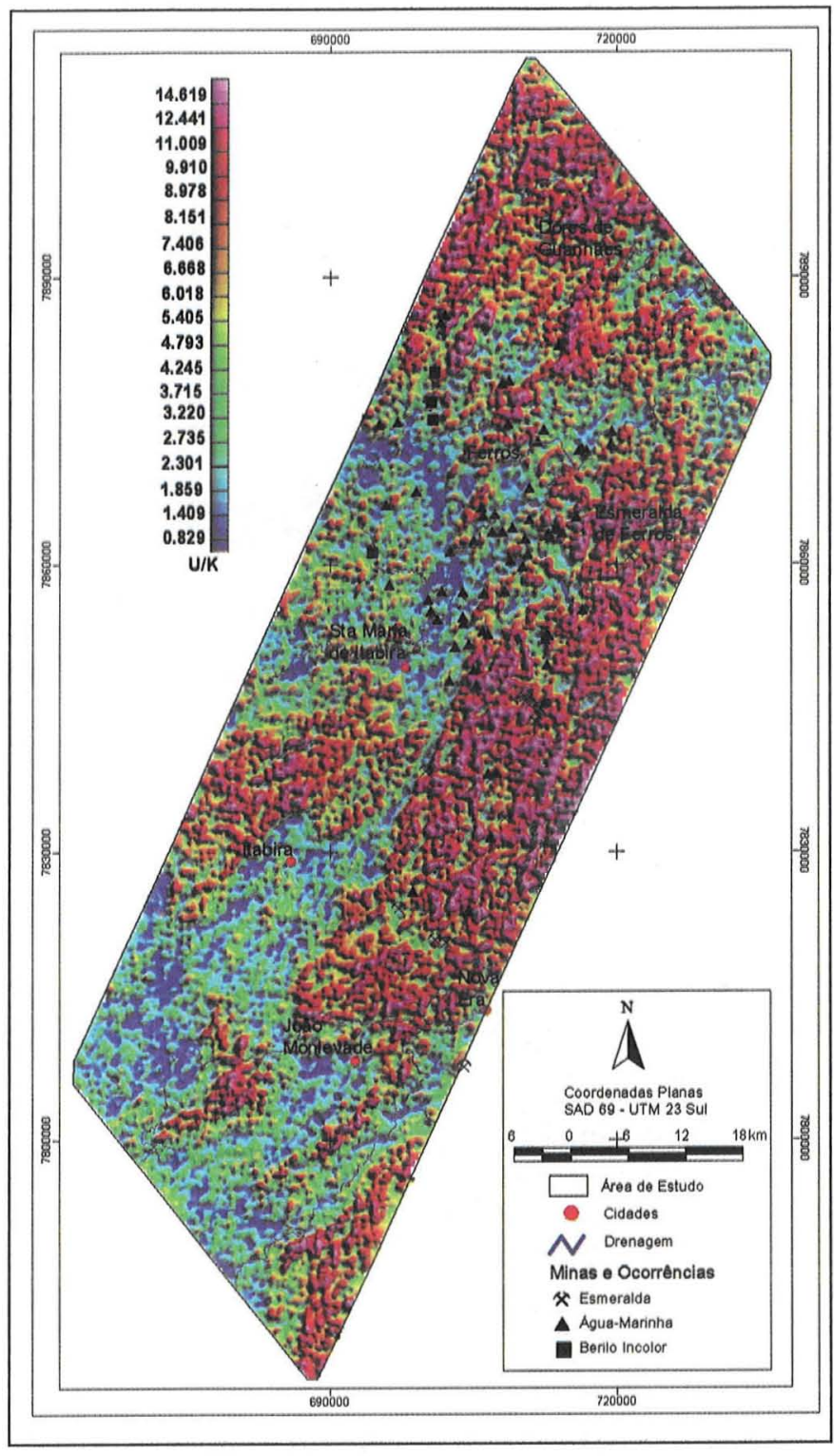

Figura 9: Imagem da razão U/Th

sas rochas mostram um enriquecimento em potássio e também mostram grandes variações composicionais internas, o que pode ser confirmado pela geologia conhecida em alguns locais e em outros não são coincidentes.

O Complexo Mantiqueira é representado pelas unidades $1 \mathrm{e}$ 2 com teores baixos de K e médios-baixos de Th e U.

Os domínios e subdomínios foram comparados aos mapas de potássio, urânio e tório. O tório, que é um bom marcador geológico, quando comparado com os mapas de contagem total, mostrou excelente correlação, delimitando os domínios e mostrando que os Granitos Borrachudos apresentam uma borda com contagens bem mais baixas do que o centro do corpo. Já quando comparado com o canal de potássio, a resposta, porém, não foi muito boa para delimitar os Granitos Borrachudos, pouco contribuindo na interpretação dessas unidades. Por outro lado, mostrou que esses granitos são caracterizados por valores relativamente baixos desse radioelemento e que os teores das unidades do embasamento são muito superiores aos destes granitos, mostrando que houve uma migração desse elemento para regiões mais baixas. $\mathrm{O}$ urânio apesar de ser facilmente remobilizado sob condições oxidantes mostrou que as maiores concentrações desse elemento estão relacionadas às rochas supracrustais da área $\mathrm{e}$

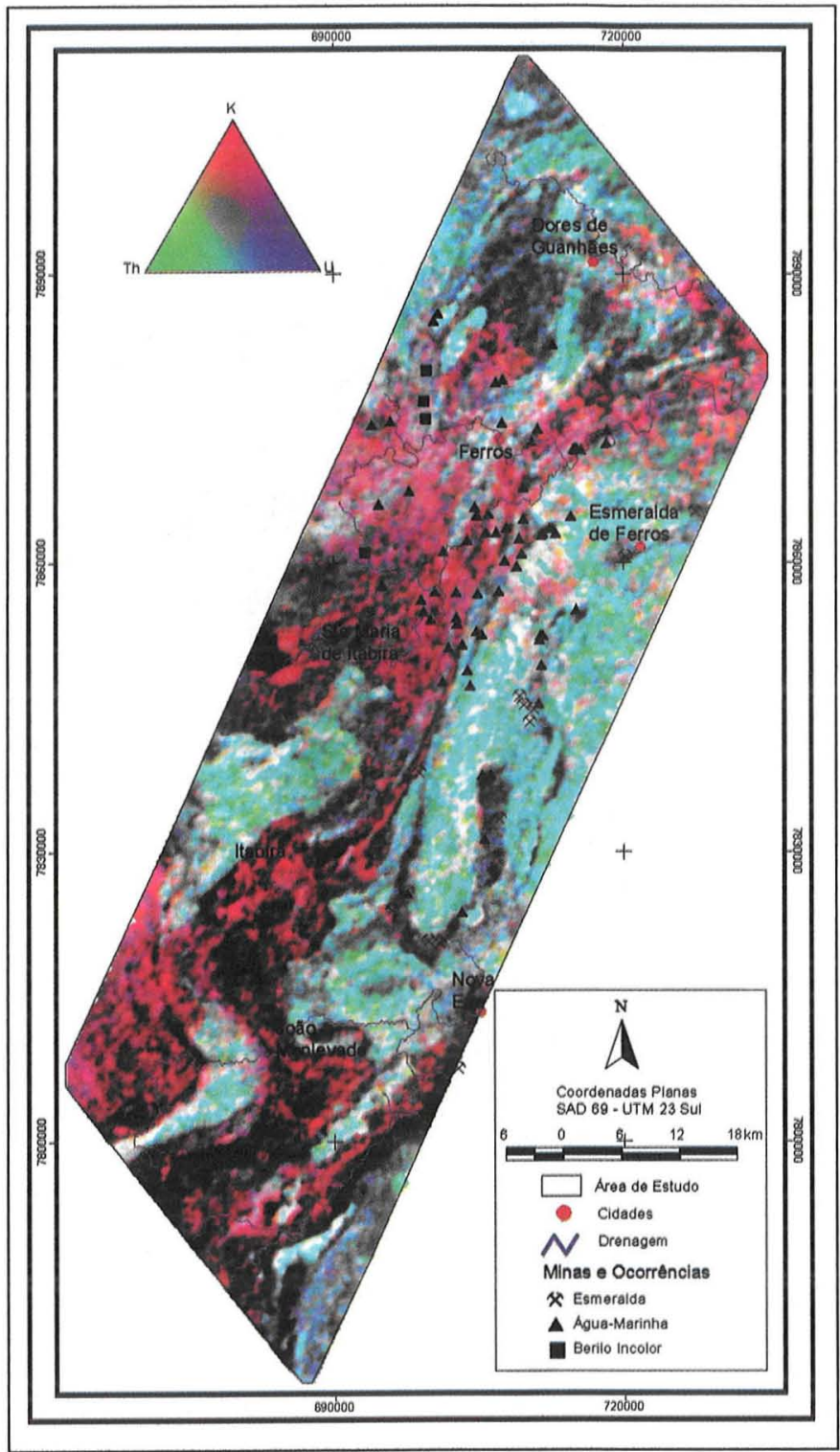

Figura 10: Imagem da Composição RGB (K/Th/U)

teores decrescentes nas rochas do embasamento. Bem como foi excelente para identificar as rochas do Complexo Mantiqueira (Sul da área).

Agradecimentos Gostaria de agradecer ao CNPq pelo apoio financeiro, à CPRM/DNPM pelo fornecimento dos dados. A Universidade de Brasília e ao Laboratório de Geofísica pelo apoio e uso dos seus equipamentos. Aos Professores Augusto César Bittencourt Pires, Claudinei Gouveia de Oliveira, Roberto Alexandre Vitória de Moraes e Marcelo de Lawrence Bassay Blum pela orientação no desenvolvimento desse trabalho. 


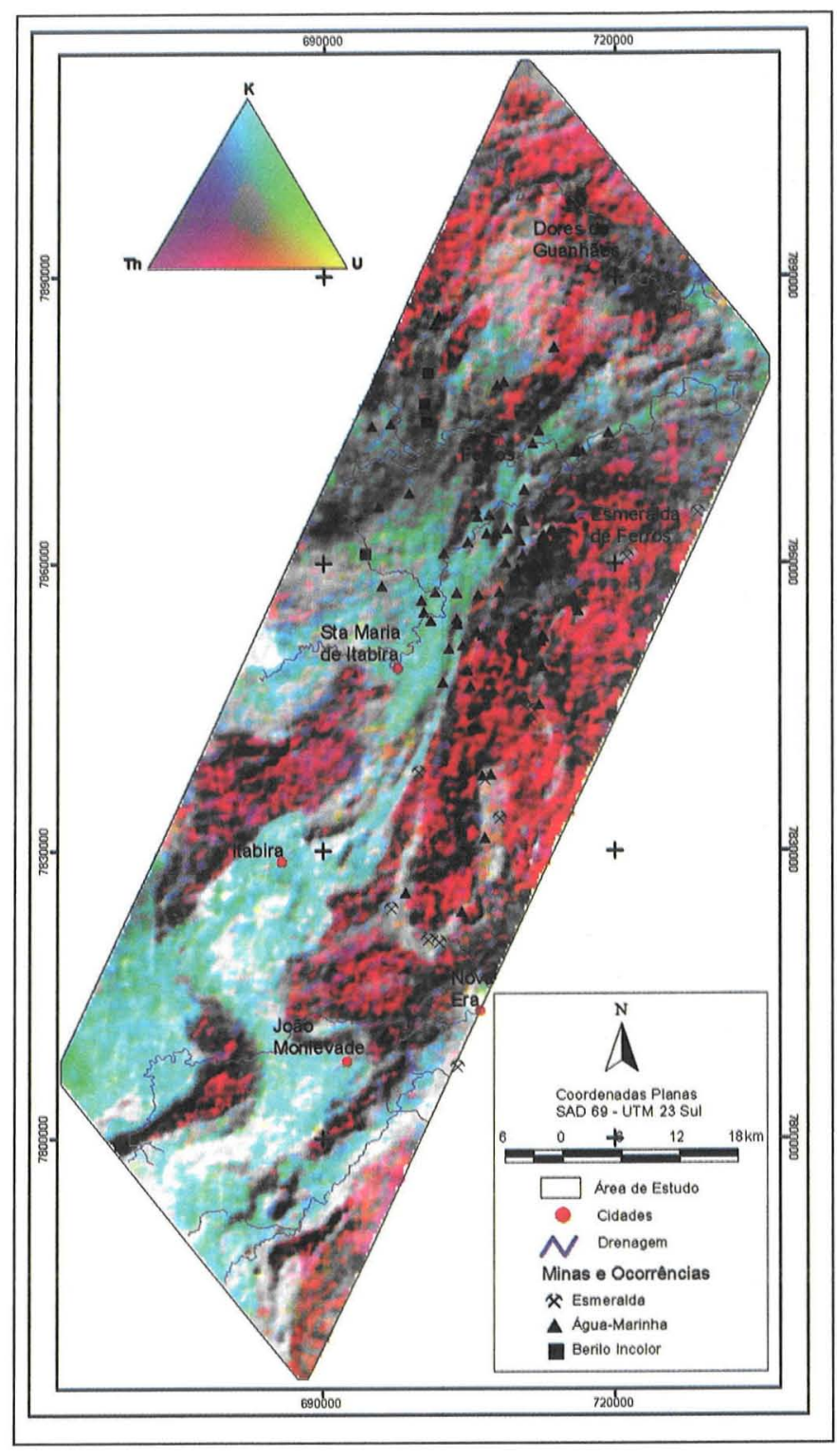

Figura 11: Imagem da composição $C M Y(K / T h / U)$

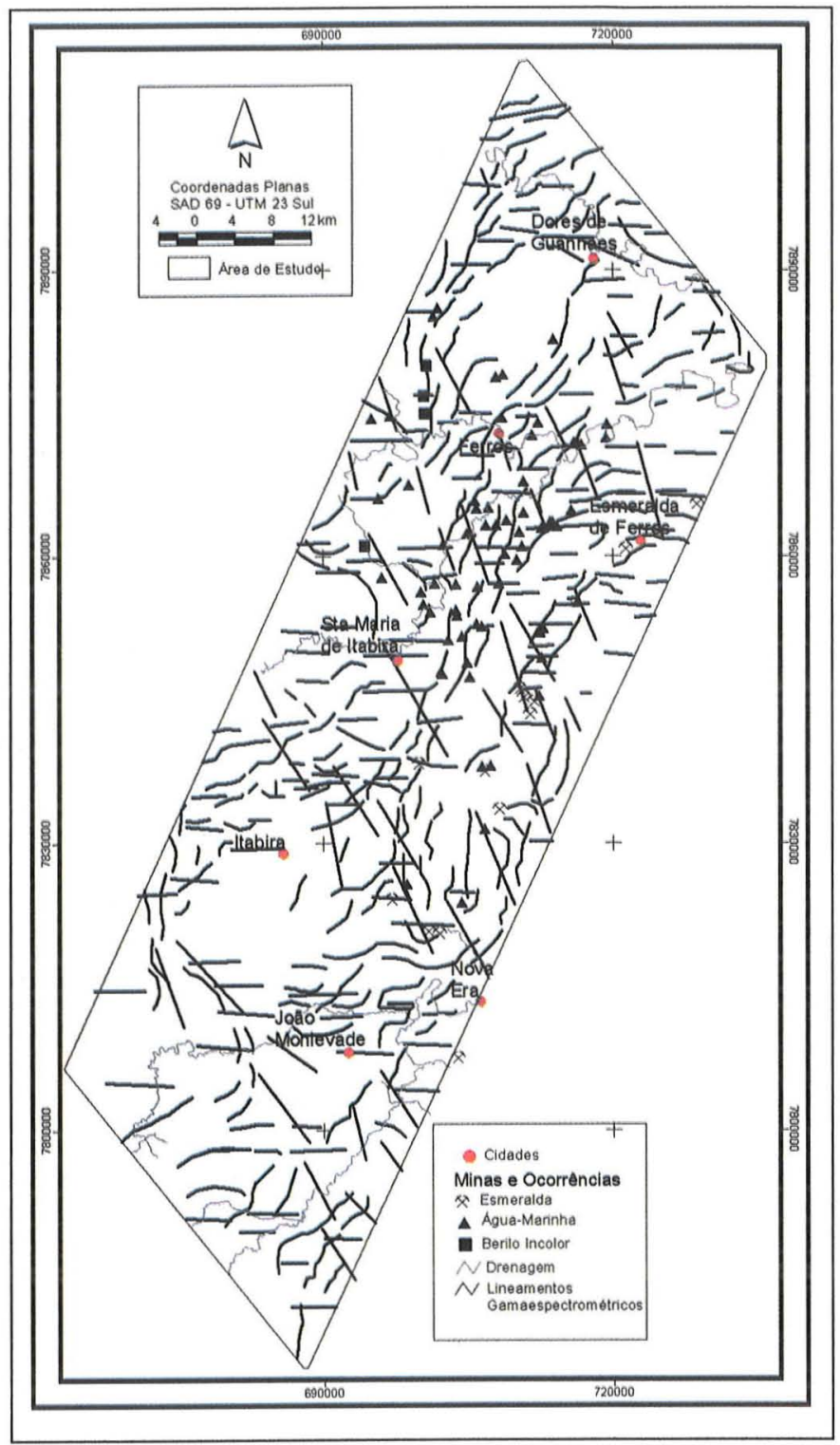

Figura 12: Mapa das estruturas gamaespectrométricas interpretadas. Observa-se que a principal tendência tem direção $N E-S W$. Estruturas NW-SE e E-W são observadas em menor quantidade 


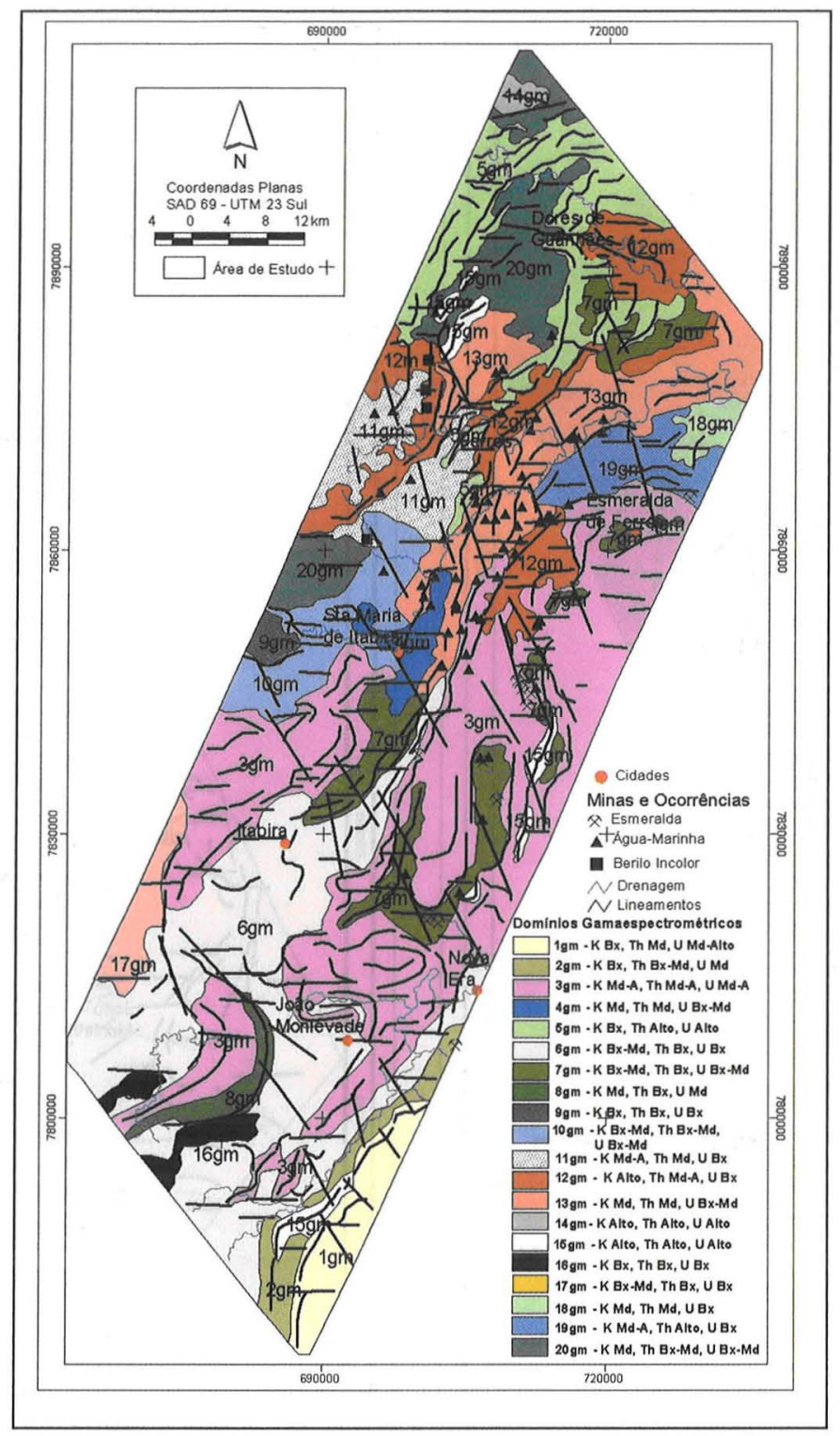

Figura 13: Mapa da integração dos domínios e lineamentos gamaespectrométricos interpretados dos diversos canais. Observa-se que grande parte das estruturas curvilineas são contatos entre as unidades geofisicas.

\section{Referências}

Almeida F.F.M. 1976. O Cráton do São Francisco e suas faixas marginais de dobramentos. In: SBG, Congresso Brasileiro de Geologia, 29, Ouro Preto, Resumos Expandidos, 241-215.

Blum M.L.B. 1999. Processamento e interpretação de dados de geofisica aérea no Brasil central e sua aplicação à geologia regional è à Prospecção Mineral. Tese de Doutoramento, Instituto de Geociências, Universidade de Brasília, Brasília, 229p.

CPRM 2004. Mapa Geológico do Brasil. CPRM. Rio de Janeiro.

Geosoft 1998. OASIS Montaj 4.2. GEOSOFT, Inc. Toronto.

Minty B.R.S. 1991. Simple Micro-Levelling for Aeromagnetic Data. Expl. Geoph. 22:591-592.

Oliveira A.A.K.\& Leite C.A.S. 2000. Folha Ipatinga, Estado de Minas Gerais, Folha SE.23-Z-D-II. Escala 1:100.000 (mapas, textos e anexos). CPRM, Belo Horizonte, 51p.
Schorscher H.D. 1991. Quadrilátero Ferrífero e Espinhaço Meridional. In: Congresso Brasileiro de Geoquímica, 3, Congresso de Geoquímica dos Países de Língua Portuguesa, 1, São Paulo, Guia de Excursões, 37-87.

Souza J.L., César-Mendes J., Bello R.M.S., Svisero D.P., Valarelli J.V. 1992. Petrographic and microthermometrical studies of emeralds in the 'Garimpo' of Capoeirana, Nova Era, Minas Gerais State, Brazil. Mineralium Deposita, 27:161-168.

Vasconcelos R.M., Metelo M.S., Mota A.C., Gomes R.D. 1990. Geofisica em Levantamentos Geológicos. Rio de Janeiro, DIGEOFCPRM.

Manuscrito A-1601

Revisão aceita em 20 de outubro de 2006 